\title{
Duplex-Specific Nuclease-Amplified Detection of MicroRNA Using Compact Quantum Dot-DNA Conjugates
}

Ye Wang, ${ }^{\circledR}$ Philip D. Howes, ${ }^{\dagger}$ Eunjung Kim, Christopher D. Spicer, ${ }^{\ddagger}{ }^{\circledR}$ Michael R. Thomas, ${ }^{\circledR}$ Yiyang Lin, ${ }^{\circledR}$ Spencer W. Crowder, Isaac J. Pence, and Molly M. Stevens*(i)

Department of Materials, Department of Bioengineering, and Institute of Biomedical Engineering, Imperial College London, London SW7 2AZ, U.K.

\section{Supporting Information}

ABSTRACT: Advances in nanotechnology have provided new opportunities for the design of next-generation nucleic acid biosensors and diagnostics. Indeed, combining advances in functional nanoparticles, DNA nanotechnology, and nuclease-enzyme-based amplification can give rise to new assays with advantageous properties. In this work, we developed a microRNA (miRNA) assay using bright fluorescent quantum dots (QDs), simple DNA probes, and the enzyme duplex-specific nuclease. We employed an

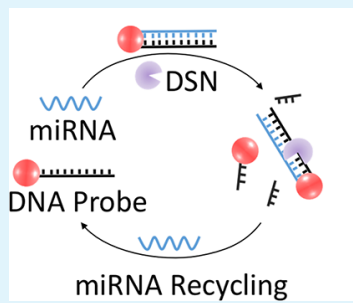

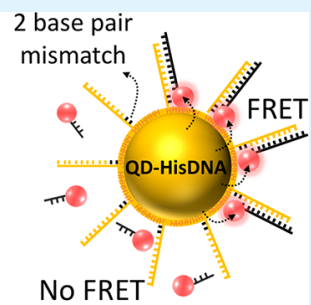
isothermal target-recycling mechanism, where a single miRNA target triggers the cleavage of many DNA signal probes. The incorporation of DNA-functionalized QDs enabled a quantitative fluorescent readout, mediated by Förster resonance energy transfer (FRET)-based interaction with the DNA signal probes. Our approach splits the reaction in two, performing the enzyme-mediated amplification and QD-based detection steps separately such that each reaction could be optimized for performance of the active components. Target recycling gave ca. 3 orders of magnitude amplification, yielding highly sensitive detection with a limit of $42 \mathrm{fM}$ (or $1.2 \mathrm{amol}$ ) of miR-148, with excellent selectivity versus mismatched sequences and other miRNAs. Furthermore, we used an alternative target (miR-21) and FRET pair for direct and absolute quantification of miR-21 in RNA extracts from human cancer and normal cell lines.

KEYWORDS: biosensing, miRNA, quantum dots, FRET, target-recycling, isothermal amplification

\section{INTRODUCTION}

The monitoring of microRNA (miRNA) expression can be used to predict the development and prognosis of many pathological conditions; ${ }^{1,2}$ therefore, miRNA detection is expected to become an important aspect of clinical diagnostics. ${ }^{1,3,4}$ However, it is particularly challenging for absolute and direct quantification of miRNAs due to their short lengths, low abundances, degradation susceptibility, and high sequence homology. Therefore, the development of novel detection approaches is of a priority.

Through the advancement of nanotechnology, ${ }^{5,6}$ a variety of nanomaterial-based detection platforms have been developed, which endeavor to meet the demanding requirements of clinical practice, ${ }^{7}$ such as reliability, accuracy, efficiency, ease of use, versatility, and cost-effectiveness. Among the most promising nanomaterials used in such platforms are colloidal semiconductor nanocrystals or quantum dots (QDs), ${ }^{8,9}$ which have demonstrated great potential in medical diagnosis ${ }^{10}$ and biological studies. ${ }^{11}$ QDs exhibit numerous unique characteristics including narrow-emission and broad-absorption spectra, high quantum yield (QY), size- or composition-tunable photoluminescence (PL), resistance to photodegradation, and a range of surface chemical modifications allowing display of various functional groups. In particular, the combination of such properties makes QDs excellent components in Förster resonance energy transfer $(\text { FRET })^{12}$ systems, when assembled and functionalized with various bioderived components (proteins, ${ }^{13-15}$ peptides, ${ }^{16,17}$ nucleic acids, etc.) for a variety of applications.

A particular avenue of interest in current research is hybrid systems composed of QDs and DNA, enabling the detection of various nucleic acid biomarkers. ${ }^{18-37}$ Comparing with some other fluorescence measurements, the use of QDs in nucleic acid detection has exhibited significant merits, including high signal-to-noise ratios, low sample consumption, and improved sensitivity. ${ }^{18}$ Indeed, the advantages of QDs for fluorescence or FRET have previously been applied to the detection of microRNAs (miRNAs). ${ }^{38}$ However, if detection relies solely on hybridization events without amplification, limits of detection (LOD) are typically restricted within the pM-tonM range. ${ }^{31,32,36,37}$ To improve on this, various isothermal amplification methods have been used in combination with QD-based nanosensors, such as exponential amplification reaction, ${ }^{25}$ target-recycled enzyme-free amplification, ${ }^{39}$ enzymatic amplification, ${ }^{26,28-30}$ and catalytic hairpin assembly

Received: May 3, 2018

Accepted: July 31, 2018

Published: August 16, 2018 
amplification. $^{40}$ Such efforts involving target or signal amplification have enabled fM-to-aM LOD to be achieved.

Despite their great promise, QDs suffer from several issues that sometimes restrict performance in biosensing systems. The biggest challenge is maintaining colloidal and fluorescence stability in aqueous biological environments. ${ }^{12}$ To this end, QD surfaces must be carefully modified with hydrophilic ligands to confer solubility and dispersity in complex biological solutions. A particular complication of relevance to the present work is that the conditions required for enzyme-mediated amplification are typically not favorable for QD stability and performance. Many enzyme solutions and incubation buffers have thiolated species (e.g., dithiothreitol (DTT)) added to stabilize the enzyme; however, these species are particularly harmful to QDs due to the inherent attraction to QD surfaces, ${ }^{41}$ with subsequent displacement of attached species ultimately leading to colloidal instability. ${ }^{42,43}$ Enzyme storage and reaction buffers will typically come with a variety of ions present, for example $\mathrm{Na}^{+}, \mathrm{K}^{+}$, and $\mathrm{Mg}^{2+}$, which can destabilize the QDs by charge screening and interference with exciton recombination. ${ }^{44,45}$ Temperature stability is a particular problem when using QDs in sensing systems where enzymemediated amplification is performed, as temperatures exceeding $50{ }^{\circ} \mathrm{C}$ are commonly employed. As a result, there is a need to design sensing strategies that can utilize both QDs and enzymes to take maximum advantage of these high-performance components.

FRET is highly distance dependent $\left(1 / r^{6}\right.$, where $r$ is the separation distance between donor and acceptor). This dependence tends to complicate the facile application of QDs, as it necessitates that the surface coating must be of minimal thickness, introducing an inherent compromise between QD protection and FRET functionality. ${ }^{12}$ Commercial streptavidin-coated QDs (SA-QD) ${ }^{25,28}$ have often been used in QD-DNA biosensing systems. These enable quantitative attachment of DNA probes without depleting QD brightness. ${ }^{18}$ However, there is low FRET efficiency due to the relatively large size of streptavidin (ca. $5 \mathrm{~nm}$ ), which greatly increases the overall distance between the QD and its FRET partners on DNA probes. This lowers FRET efficiency and the ultimate sensing limit. Unfortunately, direct attachment of DNA to QDs does not typically yield very stable particles (in contrast to gold nanoparticles), so this is not commonly a viable option. There has been great progress in the design of compact surface ligands that stabilize QDs and facilitate bioconjugation. However, there is still progress to be made for QDs to become versatile enough for use in the most challenging sensing conditions, such as when coemployed with enzymes.

In this work, we assess the utility of coemploying enzymemediated target recycling for miRNA detection and fluorescent QDs as a sensitive signal transduction agent. Considering the points discussed above, we set out to develop a miRNA detection mechanism following some specific design criteria: (1) to separate the enzyme incubation step from the QD incubation and readout, so that the two reactions could be optimized individually to maximize performance; (2) to have a homogenous one-pot assay that did not require any filtration or cleaning steps; (3) to have a universal detection mechanism that is not sequence-specific and that can potentially run in parallel in a single solution (toward multiplexing); and (4) to maximize FRET sensitivity by minimizing the donor-acceptor separation distance.
We have developed an isothermal target-recycling-based miRNA detection mechanism using a single enzyme (duplexspecific-nuclease (DSN)), ${ }^{46}$ with a QD-based readout. Various isothermal amplification methods have been developed for miRNAs analysis, such as loop-mediated isothermal amplification (LAMP), rolling circle amplification (RCA), and hybridization chain reaction (HCR). LAMP has shown outstanding specificity in a one-step reaction with a group of target-specific primers; however, this technology has several intrinsic disadvantages such as complex primer design and nonspecific amplification; RCA is an enzymatic process that can generate superlong single-stranded DNA (ssDNA) molecules, but it is very time-consuming because an additional ligation procedure is always required before amplification. Moreover, polymerases are easily inhibited by the accumulated pyrophosphate byproduct. The enzyme-free HCR method is able to provide isothermal molecular signal amplification in varied settings, however, precise design of the hairpins is needed, but systematic guidelines for designing hairpin sequences are lacking. Besides, some nonspecific amplification without target miRNA is typically observed. DSN-based target recycling, which has emerged as a versatile component in developing bioanalytical strategies, has serially been applied for quantitative detection of miRNAs owing to its sensitivity, specificity, short assay time, and lower contamination risk. DSN shows a strong preference for digesting DNA strands in doublestranded DNA or in DNA-RNA hybrid duplexes but does not show sequence specificity or cleave single-stranded DNA or RNA. Additionally, it discriminates between fully matched and slightly mismatched short duplexes.

Our approach splits the reaction in two, performing the DSN-mediated amplification and QD-based detection steps separately such that each reaction can be optimized for performance of the active components. The assay is one-pot and homogenous, with no washing or filtration. The enzyme is not sequence-specific, and the single cascades are driven by specific base-pairing of complementary sequences; therefore, the mechanism should be universal and multiplexable. Finally, FRET is maximized by employing QDs with a compact surface layer and by using FRET probes that bind to the QDs in a proximal orientation, minimizing donor-acceptor separation, which is difficult to obtain using typical "sandwich" approaches. To show the method versatility, we developed configurations for detecting miR-148 (a circulating miRNA significantly dysregulated during H1N1 infection ${ }^{47}$ ) and miR21 (which is upregulated in several pathological conditions such as cancer and cardiovascular diseases and plays a crucial role in the process of cell proliferation, cell invasiveness, and angiogenesis ${ }^{48}$ ). By systematically exploring the DSN-based cleavage reaction and QD-FRET-based signal readout, we have achieved a detection limit of $42 \mathrm{fM}$ (or $1.2 \mathrm{amol}$ ) of miR-148 in buffer, with excellent selectivity versus mismatched sequences and other miRNAs. Finally, we employed a separate system with a different FRET pair to detect miR-21 in small RNA extracts from human cancer and normal cell lines. Overall, this work presents a sensitive miRNA detection strategy, capable of functioning effectively during coemployment of enzymes and QDs.

\section{MATERIALS AND METHODS}

Materials, reagents, detailed experimental process, and instrumentation used in the current work are listed in the Supporting Information. 
Scheme 1. Schematic Representation of miRNA Detection Based on DSN-Assisted Signal Amplification and QD-FRET Step 1. DSN-mediated target recycling

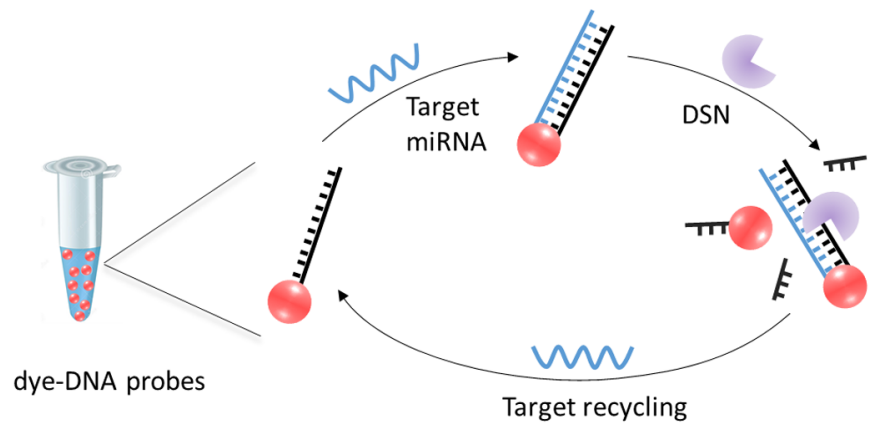

Step 2. QD-assisted selective hybridization and FRET signal generation

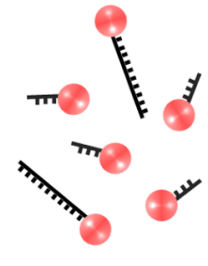

A mixed population of intact and cleaved dye-DNA probes

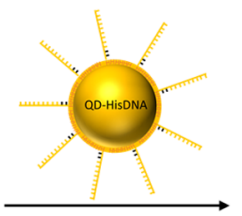

QD-HisDNA nd .

Assembly of $\mathrm{His}_{6}$-Tag DNA onto QDs. Oleic acid-capped $\mathrm{CdS}_{x} \mathrm{Se}_{1-x} / \mathrm{ZnS}$ (core/shell) QDs (525 or $570 \mathrm{~nm}$ emission) in organic solvent were made water-soluble through a ligand-exchange reaction with a dihydrolipoic acid-based zwitterionic ligand as previously described by Medintz et al. ${ }^{49}$ Chemoselective, anilinecatalyzed hydrazone coupling chemistry ${ }^{50}$ was then used to conjugate a hexahistidine $\left(\mathrm{His}_{6}\right.$ ) peptide to amine-functionalized DNA (HisDNA), which allowed them to ratiometrically self-assemble onto the hydrophilic QDs. For QD-HisDNA preparation, QDs were mixed with the indicated molar ratios of HisDNA in borate buffer (50 $\mathrm{mM}, \mathrm{pH} 8.3$ ) and incubated for $30-60 \mathrm{~min}$ prior to use. Successful self-assembly was confirmed by gel electrophoresis and analysis of FRET interactions.

DSN Activity on DNA-miRNA Duplexes. The reaction conditions (temperature and concentrations of $\mathrm{MgCl}_{2}, \mathrm{DTT}$, and the DSN enzyme) for the DSN cleavage step were first optimized. Here, a dual-labeled DNA probe with a black hole quencher 3 (BHQ3) at one end and the dye Alexa Fluor $594\left(\mathrm{AF}_{594}\right)$ at the other was used. In a typical DSN cleavage assay, the reaction was carried out in a final volume of $30 \mu \mathrm{L}$ containing $40 \mathrm{nM}$ DNA probe, various target miRNA concentrations, and $0.01 \mathrm{U} \mu \mathrm{L}^{-1} \mathrm{DSN}$ in the optimal buffer (50 mM Tris- $\mathrm{HCl}, 15 \mathrm{mM} \mathrm{MgCl} 2$, and $0.5 \mathrm{mM} \mathrm{DTT,} \mathrm{pH}$ 8.0). The reaction was carried out using a thermomixer at $60{ }^{\circ} \mathrm{C}$ for 2 $\mathrm{h}$ and stopped by adding ethylenediaminetetraacetic acid (EDTA) with incubation at $60{ }^{\circ} \mathrm{C}$ for $5 \mathrm{~min}$ ( $15 \mathrm{mM}$ EDTA in final mixture). The reaction mixture was then transferred to a black polystyrene halfvolume Corning 96-well plate (Sigma) for the detection procedure.

Detection of DNA Probe through QD-HisDNA-Selective Hybridization. QD-HisDNA conjugates ([QD] $=2 \mathrm{nM}$, [HisDNA] $=30 \mathrm{nM})$ in nuclease-free duplex buffer $(30 \mathrm{mM} \mathrm{N}-(2-$ hydroxyethyl)piperazine- $N^{\prime}$-ethanesulfonic acid, $100 \mathrm{mM}$ potassium acetate, $\mathrm{pH}$ 7.5) were added to the above DSN mixture (final concentration of QDs was $1 \mathrm{nM}$ ) and incubated at room temperature (RT) for 30-60 min. Fluorescence emission was recorded for both the QD and the dye using a SpectraMax M5 microplate reader (Molecular Devices).

Specificity Test. The specificity of the proposed assay was evaluated by analyzing samples containing $100 \mathrm{fM}, 10 \mathrm{pM}, 100 \mathrm{pM}, 1$ $\mathrm{nM}$, and $20 \mathrm{nM}$ miR-133a, miR-378, miR-423, and miR-148 with one and three base pair mismatches. $\mathrm{AF}_{594}$-labeled ( $\left.100 \mathrm{nM}\right)$ DNA probe was used under the optimal condition for each assay. The miRNAs sequences are listed in Table S1.

Preparation of Cell Culture and RNA Isolation. Human cancer cell lines (MCF-7 and MDA-MB-231) and noncancerous cells (human embryonic kidney cells HEK 293T) were obtained from ATCC as described. ${ }^{51}$ RNA isolation from all cells, cDNA synthesis, and reverse transcription polymerase chain reaction (RT-PCR) using commercial kits were conducted according to the manufacturer's instructions. A detailed description can be found in our previous work. $^{51}$ RNeasy mini spin columns were then used to separate miRNA-enriched fractions, small RNA species below $200 \mathrm{nt}$, from the total RNA aqueous solution, and the extracted miRNA was finally obtained by purification with an RNeasy mini cleanup kit. The concentration of miR-21 in the extracted miRNA was determined by RT-PCR

Quantification of miR-21 in RNA Extracts by RT-PCR and DSN-Assisted QD-FRET. A commercial kit (miScript SYBR Green PCR kit) was used for quantification of miR-21 by RT-PCR. The standard curve of PCR was obtained using synthetic miR-21 of known concentration. A detailed experimental description can be found in our previous work. ${ }^{51}$

For miR-21 detection using the DSN-assisted QD-FRET assay, the RNA extract was added into a mixture of $40 \mathrm{nM}$ Cy3-DNA probe and $0.3 \mathrm{U}$ DSN in the reaction buffer $(30 \mu \mathrm{L}$ in total $)$, and the reaction was stopped by EDTA after $2 \mathrm{~h}$ at $60{ }^{\circ} \mathrm{C}$. $\mathrm{QD}_{525}$-HisDNA conjugates in nuclease-free duplex buffer were added to the above DSN mixture (final concentration of QDs was $1 \mathrm{nM}$ ) and incubated for 30-60 min at RT. Fluorescence emission was recorded for both $\mathrm{QD}_{525}$ and $\mathrm{Cy} 3$ using a SpectraMax M5 microplate reader (Molecular Devices).

\section{RESULTS AND DISCUSSION}

Principle of miRNA Detection. A two-step mechanism for miRNA detection is proposed in Scheme 1: (1) DSNmediated dye-labeled DNA probe degradation and (2) QDassisted FRET signal generation. In step one, the target miRNA hybridizes with the dye-labeled DNA probe, forming heteroduplexes, which are then subjected to a DNA-specific 
(A)

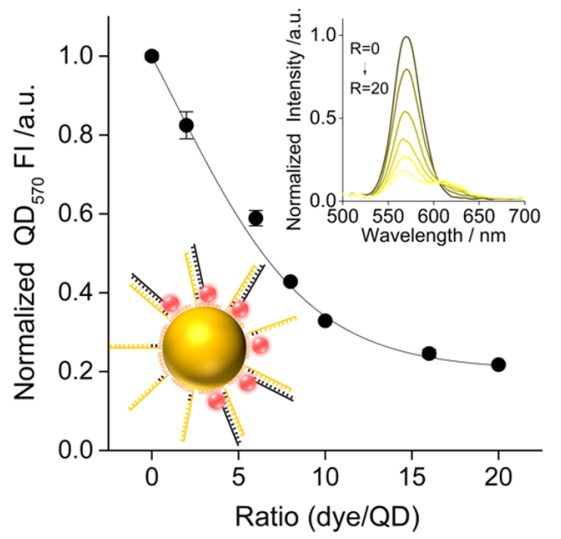

(C)

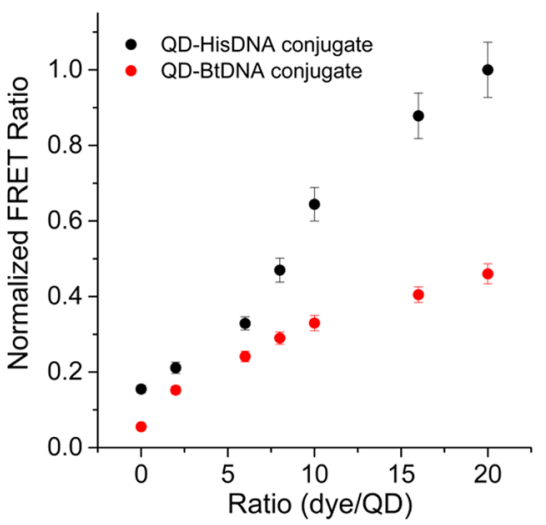

(B)

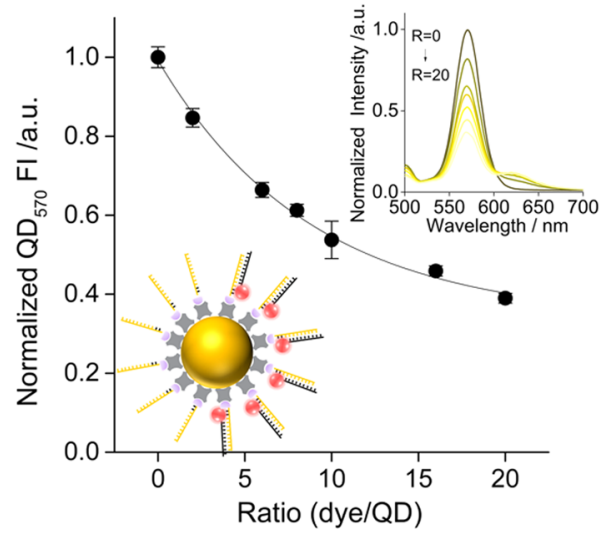

(D)

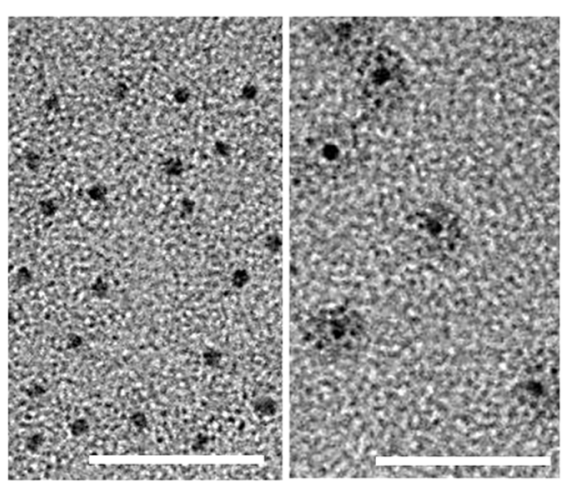

Figure 1. Comparative FRET data for the two $\mathrm{QD}$ conjugate systems (HisDNA- $\mathrm{QD}_{570}-\mathrm{AF}_{594}$ vs $\left.\mathrm{BtDNA}-\mathrm{QD}_{570}-\mathrm{AF} \mathrm{F}_{594}\right)$. (A) $\mathrm{QD}-\mathrm{HisDNA}$ conjugate. (B) QD-BtDNA. Insets show the corresponding normalized fluorescence emission spectra. (C) FRET ratio comparison between the two systems. FRET ratio $=I_{\text {dye }} / I_{\mathrm{QD}}$. (D) TEM images of zwitterionic ligand (left) and streptavidin (right)-coated QD. The particles were negatively stained with uranyl acetate. Both were tested in duplex-nuclease-free buffer. Scale bar: $50 \mathrm{~nm}$. All error bars in the figures indicate standard deviations, $N=3$.

cleavage reaction by DSN, leaving the miRNA intact. The released miRNA can repeatedly and rapidly bind to other DNA probes in the solution; therefore, one target miRNA strand leads to cleavage of thousands of DNA probes within $30 \mathrm{~min}$, under optimal conditions. ${ }^{52}$ In step two, the remaining uncleaved DNA probes are hybridized with HisDNA-QDs to form QD-dye conjugates, generating a significant change in both $\mathrm{QD}$ and dye PL intensity (FRET signal). Importantly, cleaved probes cannot hybridize. The result is a positive correlation between the concentration of miRNA and the intensity of $\mathrm{QD}$ fluorescence brightness $\left(I_{\mathrm{QD}}\right)$ or an inverse relationship between miRNA and the FRET signal $\left(I_{\text {dye }} / I_{\mathrm{QD}}\right)$.

Considering the design criteria presented in the introduction, our miRNA detection mechanism presents the following advantages: (1) The two steps of the assay are controlled to favor either the enzyme or the QD. Step one is performed at high temperature $\left(60{ }^{\circ} \mathrm{C}\right)$ in a high $\mathrm{Mg}^{2+}$ concentration (favorable to the DSN), whereas step two is performed at RT with EDTA added to sequester the $\mathrm{Mg}^{2+}$ (favorable to the QD). In this way, the performance of the two key components is tailored to allow optimal performance of the full assay. (2) No washing or filtration is required between steps 1 and 2 . The temperature is simply decreased from $60{ }^{\circ} \mathrm{C}$ to room temperature, and EDTA is added, which quickly sequesters $\mathrm{Mg}^{2+}$ and deactivates the DSN. (3) The detection cascade relies on highly specific interactions between the target miRNA and the simple component oligonucleotides and on nonspecific detection and cleavage behavior of the DSN. Therefore, the system should be universal (working with a wide variety of miRNA sequences) and multiple signaling cascades should work in parallel. (4) To minimize the separation distance between donor and acceptor in the FRET system, we used compact QD-DNA conjugates with minimal surface layer thickness, synthesized by procedures based on those by Medintz et al., ${ }^{49}$ which have shown their efficacy in various demanding biological applications. ${ }^{53-55}$ Furthermore, the dyelabeled DNA probe was able to bind with the dye oriented proximal to the $\mathrm{QD}$, bringing the dye as close as possible to the QD surface.

The proposed system offers some further general advantages. First, the reaction does not require temperature cycling (as used in polymerase chain reaction (PCR)-based systems), with incubation at a constant moderate temperature (60 ${ }^{\circ} \mathrm{C}$ ) instead, followed by room temperature detection. Second, target recycling does not suffer from nonspecific priming and amplification that is typical in isothermal amplification techniques using polymerase enzymes to synthesize new nucleic acids, only a single enzyme and no nucleotides are required, which simplifies the mechanism compared with typical isothermal amplification techniques. Most importantly, the carefully designed two-step assay is optimized for both the enzymatic reaction and the QD-FRET assay. It is important to 
(B)

(A)
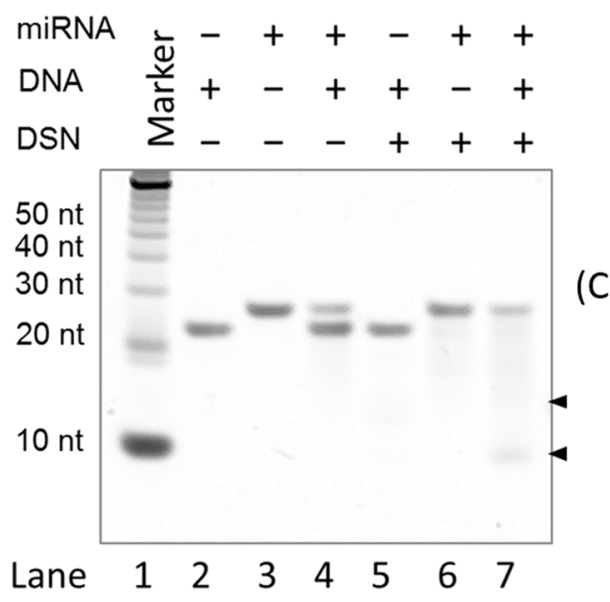

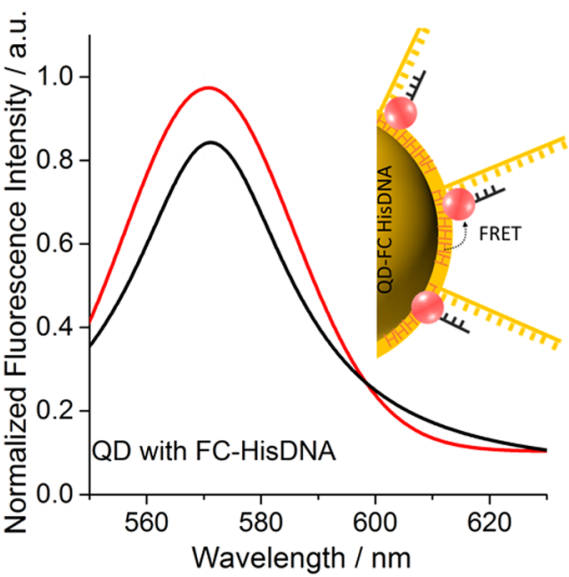

C)

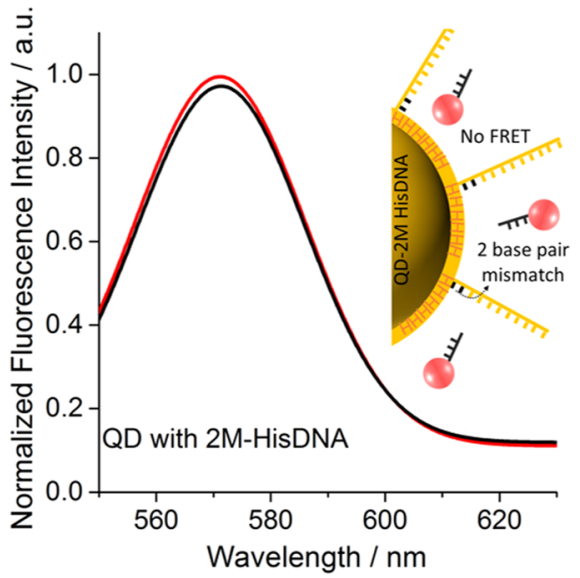

Figure 2. (A) Twenty percent dPAGE gel electrophoresis analysis of DNA probe and miRNA with DSN. Comparison of dye-labeled DNA probe hybridized with two types of HisDNA-QD surface: (B) fully complementary HisDNA or (C) HisDNA with two mismatches in the absence (red) and presence (black) of DSN. Sequence of the dye probe: 5'-AF 594 -ACA AAG TTC TGT AGT GCA CTG A-3', sequence of amine-DNA (FC): 5'-GTG CAC TAC AGA ACT TAA A-amine-3', and sequence of amine-DNA (2 M-No1): 5'-GTG CAC TAC AGA TAT TAA A-amine-3'.

note that there are some challenges associated with using DSN. For example, it is limited to linear signal amplification, it requires a minimum of $10 \mathrm{bp}$ in hybrid substrates for effective cleavage, and it requires divalent cations, making it incompatible with some applications. Nevertheless, its inherent advantages make it an excellent candidate in many sensing systems.

Characterization of $\mathrm{His}_{6}$-Modified DNA Assembly on QDs and FRET Study. The assembly of DNA on QDs was achieved by conjugating $\mathrm{His}_{6}$-tag DNA onto zwitterionicligand-protected QDs. To this end, a lipoic acid-derived zwitterionic ligand was synthesized to modify the QD surface via phase transfer, which offers good colloidal stability to the QDs. ${ }^{49}$ As shown in Figure S1C, the fluorescence and absorption spectra of the QDs showed only a few nanometer shift after phase transfer, likely due to surface etching of the $\mathrm{ZnS}$ shell. ${ }^{56}$ This incomplete surface passivation would generally result in a decrease in the fluorescence quantum yield (QY) of QDs. Similar to others, the relative QYs of $\mathrm{CdS}_{x} \mathrm{Se}_{1-x} / \mathrm{ZnS}$ core/shell QDs after ligand exchange dropped to ca. half $(10-20 \%$ in borate buffer) of that measured in hydrophobic solvents $(40-50 \%$ in toluene). The hydrodynamic diameter of ligand-coated $\mathrm{QD}_{570}$ was measured to be $9 \mathrm{~nm}$ by dynamic light scattering, demonstrating the good dispersibility of the hydrophilic QDs, confirmed by transmission electron microscopy (TEM) (Figure S1D inset). QDs with such short ligands can be functionalized with biomolecules through either covalent attachment or metalaffinity coordination, while retaining high FRET efficiency. ${ }^{49,55,57,58}$

To take advantage of polyhistidine-driven affinity to the $\mathrm{Zn}$ rich QD surface, amine-terminated DNA was functionalized with a hydrazine motif, and then ligated to an aldehydeterminated $\mathrm{His}_{6}$ peptide sequence via aniline-catalyzed hydrazine formation. ${ }^{59,60}$ Polyhistidine allows rapid binding (less than $30 \mathrm{~min}$ ) to QDs via metal-affinity coordination, ${ }^{61,62}$ which offers rapid high-affinity self-assembly with control over the number and orientation of moieties assembled per QD. Importantly, it can be used directly without further purification. Furthermore, the histidine-Zn interaction is less sensitive to DTT as it does not rely on thiol-binding and thus constructs are relatively stable in the DTT-rich buffer conditions used herein. Successful self-assembly of QDHisDNA conjugates was then checked by agarose gel electrophoresis and subsequent FRET analysis. As shown in Figure S2, the shift of the QD-HisDNA conjugate bands reflects the electrophoretic mobility changes resulting from the increased number of DNA molecules on the QD surface. A gradual decrease in the migration of QD-HisDNA bands was observed with the increase of HisDNA/QD ratio, indicating efficient assembly of HisDNA onto the QDs. Such bands indicate a low distribution of DNA loading number across the 
(A)

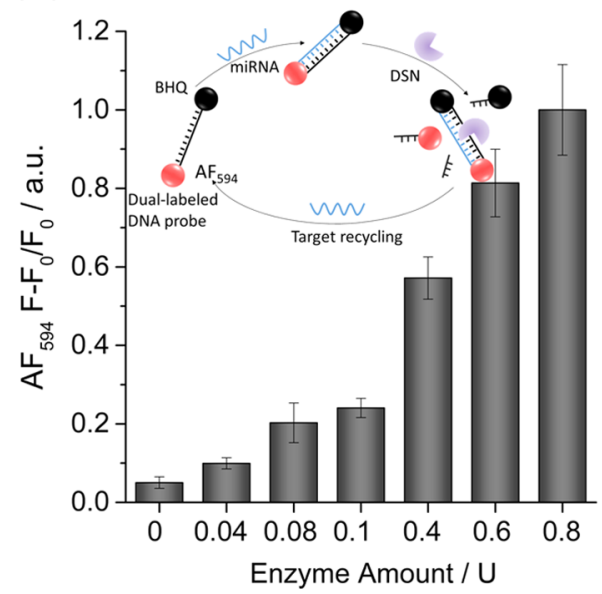

(B)

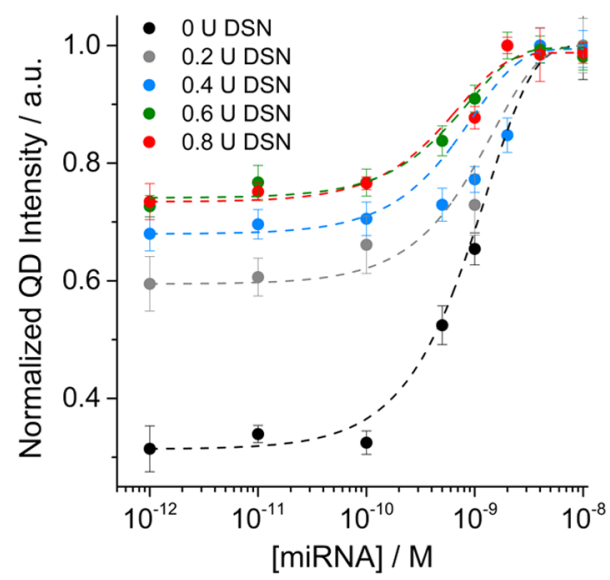

Figure 3. Effect of DSN dose on assay performance. (A) Dual-labeled system in the DSN cleavage step showed that normalized fluorescence intensity ( $F$ and $F_{0}$ are the $\mathrm{AF}_{594}$ fluorescent intensities in the presence and absence of the target) increases rapidly when the dosage of DSN increased from 0 to $0.8 \mathrm{U}$ within the same time. (B) DSN in the reaction mixture affects the next QD-FRET step: with the same concentration of target miRNA, more DSN resulted in higher QD fluorescence, which indicated less FRET occurring in the system. $\left[A F_{594}-D N A\right]=40 \mathrm{nM},\left[\mathrm{QD}{ }_{570}\right]$ $=1 \mathrm{nM},[$ HisDNA $]=15 \mathrm{nM}$. All error bars in the figures indicate standard deviations, $N=3$.

population, likely following a Poisson distribution. FRET interactions between the central QD donor and dye acceptors were examined by hybridizing the complementary acceptor DNA probe to the QDs.

To verify the benefit of QD-HisDNA bioconjugation, streptavidin-coated QDs (emission $570 \mathrm{~nm}$ ) with biotinylated DNA (BtDNA) were used as a comparison for FRET analysis. FRET interactions were recorded while increasing the ratio of $\mathrm{AF}_{594}$-labeled DNA probes self-assembled per $\mathrm{QD}$ donor. As shown in Figure 1, conjugation of the DNA probe to the QD quenched the donor fluorescence at $570 \mathrm{~nm}$, while at the same time enhancing the $\mathrm{AF}_{594}$ acceptor fluorescence at $615 \mathrm{~nm}$ through FRET. For the QD-HisDNA conjugate, a significant decrease in $\mathrm{QD}$ donor PL was observed with increasing acceptors, and more than $50 \%$ fluorescence was quenched at ratios ca. 6. In contrast, the $\mathrm{QD}-\mathrm{BtDNA}$ conjugate needed more than 12 acceptors to achieve the same quenching effect. A direct comparison is shown in Figure 1C, plotting FRET ratios $\left(\right.$ FRET ratio $\left.=I_{\text {dye }} / I_{\mathrm{OD}}\right)$. The increase in FRET ratio is clearly superior for the HisDNA-QDs, likely as a result of the thick streptavidin layer on the QD surface. As shown in Figure $1 \mathrm{D}$, the streptavidin layer showed a size of ca. $5 \mathrm{~nm}$ by TEM, which is significantly larger than that of the ligand used in the current system (ca. $2 \mathrm{~nm}){ }^{49}$ Furthermore, the histidine peptide places the dye acceptor very close to the QD surface, resulting in excellent energy transfer and high FRET efficiency. Moreover, as shown in Figure 1A, the FRET between $\mathrm{QD}_{570}$ (donor) and $\mathrm{AF}_{594}$-DNA (acceptor) reaches a maximum when the dye/QD ratio reached ca. 15. Further addition of $\mathrm{AF}_{594}$ does not significantly decrease the $\mathrm{PL}$ of $\mathrm{QD}_{570}$. We therefore determined that the optimal ratio of HisDNA on the QD surface for best FRET performance in our system is ca. 15.

DSN Catalytic Activity on DNA-miRNA Duplexes. We performed an initial test of the DSN-mediated target-recycling system using a fully complementary (FC) DNA-miRNA heteroduplex and DSN, under optimal reaction conditions, with the products analyzed by $20 \%$ denatured polyacrylamide gel electrophoresis (dPAGE). As shown in Figure 2A, DSN showed strong cleavage preference only toward DNA strands in DNA-miRNA duplexes, as previously reported. ${ }^{46,63}$
However, we observed that although the 22-base DNA strands were cleaved into smaller fragments, some of them still retained the ability to hybridize to a full-complementary (FC) HisDNA to quench QD (Figure 2B) at room temperature. This would result in a false negative result. The basis of the proposed strategy is the differential hybridization ability of short oligonucleotide fragments after DSN cleavage versus intact DNA probes ( 22 bases) to the HisDNA-QD, according to the nature of the Watson-Crick base pairing. To avoid these false negatives from the cleaved DNA fragments, two base pair mismatches $(2 \mathrm{M})$ were introduced to the HisDNA sequence at the amine-functionalized end. The mismatches will be present close to the QD surface. Therefore, while this maintained a sufficient hybridization efficiency between the HisDNA and intact DNA probe, the FRET signal caused by the cleaved fragments can be completely impaired (Figure 2C) owing to the low $T_{\mathrm{m}}$ between the cleaved fragments and the HisDNA with mismatches. It is very important to choose the appropriate position for mismatches within the HisDNA sequence because the use of a mismatched sequence will also affect the FRET efficiency between intact DNA probe and HisDNA, as shown in Figure S3, due to the $T_{\mathrm{m}}$ differences. Indeed, the discrimination ratio (the ratio of quenching efficiencies from the intact DNA versus the cleaved DNA fragment) from $2 \mathrm{M}$-HisDNA is negligible compared to that of the FC-HisDNA.

Optimization of the DSN Reaction. To maximize DSN performance, the reaction parameters including the temperature and the concentration of $\mathrm{MgCl}_{2}, \mathrm{DTT}$, and DSN were optimized. To readily measure the cleavage efficiency of DSN, we used a dual-labeled DNA probe with $\mathrm{AF}_{594}$ at one end and a BHQ3 quencher at the other end. The cleavage of DNA by DSN removed fluorescent $\mathrm{AF}_{594} \mathrm{DNA}$ fragments from the quencher fragments, resulting in a significant enhancement in the fluorescence signal. The rate of change in fluorescence intensity was therefore proportional to the activity of DSN. The highest signal was noted in the buffer containing $15 \mathrm{mM}$ $\mathrm{MgCl}_{2}$ and $0.5 \mathrm{mM}$ DTT at $60{ }^{\circ} \mathrm{C}$ (Figure S4), which is 10.6 ${ }^{\circ} \mathrm{C}$ lower than the estimated $T_{\mathrm{m}}$ of the miR-148-DNA duplex (Figure S5). Although a higher temperature facilitated faster 
(A)

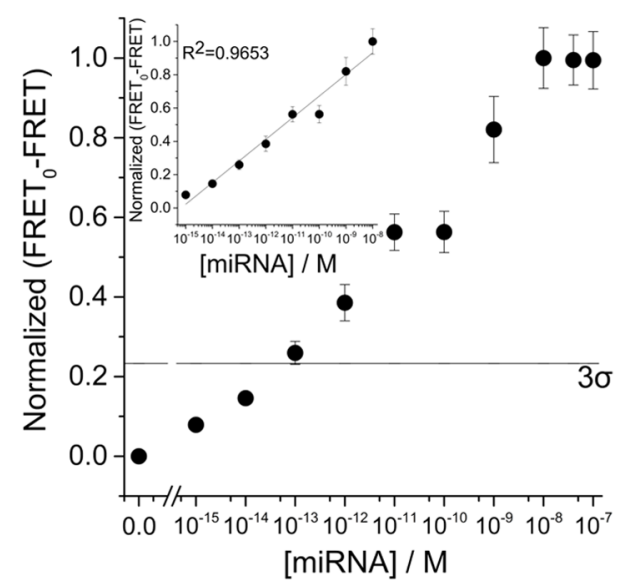

(B)

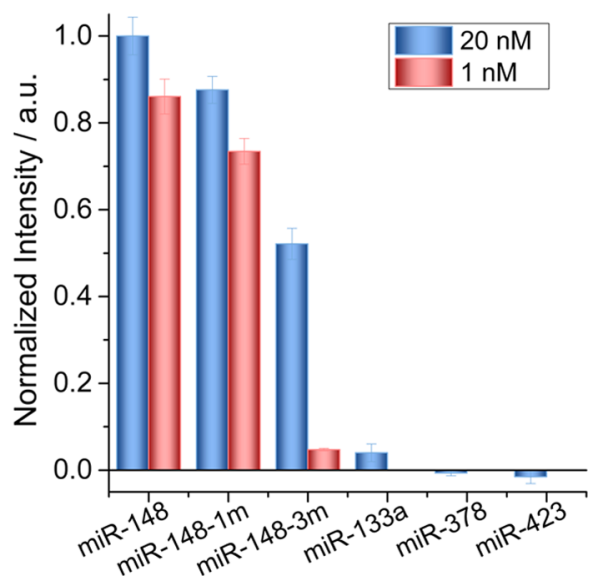

Figure 4. Sensitive and selective detection of miR-148 in pure buffer. (A) Target dose-response normalized (FRET $T_{0}-$ FRET $)$, where FRET $_{0}$ and FRET are the FRET ratio in the absence and presence of a target, FRET ratio $=I_{\text {dye }} / I_{\mathrm{QD}}$, where the QD channel at $\lambda=570 \mathrm{~nm}$ and dye channel at $\lambda$ $=615 \mathrm{~nm},\left[\mathrm{AF}_{594}-\mathrm{DNA}\right]=40 \mathrm{nM},[\mathrm{DSN}]=0.3 \mathrm{U},\left[\mathrm{QD}_{570}\right]=1 \mathrm{nM}$, and $[$ HisDNA $]=15 \mathrm{nM}$. The DSN reaction was performed at $60{ }^{\circ} \mathrm{C}$ for $2 \mathrm{~h}$ and QD-HisDNA, selective hybridization was carried out at RT for $40 \mathrm{~min}$. All error bars in the figures indicate standard deviations; $\mathrm{N}=6 .(\mathrm{B})$ Target miRNA-specific test. DNA probe $(100 \mathrm{nM})$ was incubated with 20 and $1 \mathrm{nM}$ target for $2 \mathrm{~h}$. Normalized fluorescence intensities with various miRNAs with $0.1 \mathrm{U}$ DSN, where $F_{0}$ and $F$ are the fluorescence signals without and with the miRNA target, respectively. All error bars in the figures indicate standard deviations; $N=3$.

dissociation of miRNA, it also caused denaturation of the DNA-RNA heteroduplexes, resulting in a dramatic decrease in the peak value. Other key factors are incubation time for the assay and the absolute amount of DSN used. We set out to investigate these by monitoring the change in the fluorescence signal upon addition of varying amounts of DSN enzyme versus time. As shown in Figure S6, with a fixed DSN amount, if the incubation time is sufficiently long, this cyclic reaction will repeat until all the probes are consumed (Figure S6A). DSN is an extremely thermostable enzyme, and it has been reported that $7 \%$ of its activity can be retained even after incubating at $100{ }^{\circ} \mathrm{C}$ for $30 \mathrm{~min} .{ }^{46}$ Other DSN-based assays have reported their reaction time from 30 to 120 min under various buffer conditions and temperatures. $29,51,52,64-70$ Although a longer reaction time could achieve a higher sensitivity, $2 \mathrm{~h}$ was chosen to balance the total assay time. For the amount of DSN used in the assay, the kinetics study in Figure $\mathrm{S} 6 \mathrm{~B}$ showed that fluorescence of $\mathrm{AF}_{594}$ increased rapidly with the increased DSN dose from 0 to $0.8 \mathrm{U}$. Importantly, the nonspecific background caused by DSN digesting ssDNA probes is negligible. As shown in Figure 3A, the relative signal change $\left(F-F_{0} / F_{0}\right.$, where $F_{0}$ and $F$ are the fluorescent intensities in the absence and presence of a target) kept increasing with increasing DSN. This is because the DSN enzyme has no preference toward ssDNA due to its strict cleavage specificity. This agreed with the result from dPAGE gel analysis (Figure 2A).

A further refinement of the assay was required to restrict the effect that DSN could have during the detection step when the QD-HisDNA conjugates were added. Although the addition of EDTA after the amplification reaction (which sequesters $\mathrm{Mg}^{2+}$ ions that are required for DSN to function) quenched the DSN reaction, we found that the DSN could still affect the subsequent QD-FRET detection step, as shown in Figure 3B. After DSN cleavage, we added QD-HisDNA conjugates for hybridization of the uncleaved DNA probe. With the same concentration of target miRNA, more DSN resulted in a relatively higher QD fluorescence, which indicated less FRET occurring in the system. This resulted in an impaired dynamic range without significant improvement in the assay sensitivity. When a large amount of enzyme was used, it was active on the HisDNA-DNA duplexes on the QD surface, cleaving the duplexes and releasing the dye from QD. Therefore we set out to investigate the effect of the amount of DSN on the final QDFRET ratio, as shown in Figure S7. Here, the DNA probe was incubated with varied DSN amounts without target and then QD-HisDNA conjugates were added after deactivation of DSN by sequestering $\mathrm{Mg}^{2+}$ using EDTA. As can be seen from Figure S7, the FRET ratio kept decreasing with the increasing DSN concentration, in agreement with Figure 3B. Although a greater DSN concentration would greatly speed up the cleavage reaction, it would diminish the subsequent QDFRET efficiency, thus affecting the assay sensitivity. To achieve a high sensitivity within a reasonable time frame, we chose 0.3 U DSN in our experiment.

Optimization of the Dye-Labeled DNA Probe. As can be seen from Scheme 1, the initial dye-labeled DNA probe concentration was significantly important for the assay sensitivity. To achieve the best assay performance, the concentration of DNA probe should be kept high enough to ensure that the cleavage of DNA only results from the target miRNA hybridization process, as well as to achieve a wide dynamic range for the assay. On the other hand, a low concentration of DNA probe in the system should yield a distinguishable FRET signal at low miRNA concentrations. As noted from Figure 1A, above the linear dose-response zone, the FRET ratio slowly levels off. Therefore, DNA probeinduced FRET of QD-HisDNA without the DSN amplification was investigated under the same buffer conditions. Most importantly, QD-HisDNA conjugates were found unstable and quenched in the pure DSN optimal buffer (data not shown); however, the design of a two-step assay, using EDTA to sequester all of the free $\mathrm{Mg}^{2+}$ ions before adding the QDs, greatly improved their stability and fluorescence. Figure S8 shows the FRET ratio of a mixed solution containing QDHisDNA in nuclease-free duplex buffer with varying amounts 
of DNA probe in the DSN reaction buffer. Importantly, the same final EDTA concentration was used. With an increasing amount of DNA probe, the FRET ratio increased due to QDdye FRET. However, the FRET ratio in this mixture buffer condition was much lower than the one tested in the ideal buffer in Figure 1C. This was due to interference and impairment by the enzyme buffer. The FRET ratio in Figure S8 changed in response to different concentrations of DNA probe. We found a $40 \mathrm{nM}$ concentration of the initial dyelabeled DNA probe to be enough to maintain a compromise between the dynamic range and the sensitivity of our assay and therefore chose this for the following detection of miRNA.

Detection Performance of the Full Assay. Next, we combined the two assay steps, the DSN amplification and QDFRET detection, for sensing miRNA-148. We chose a $\mathrm{QD}_{570}$ and $\mathrm{AF}_{594}$ FRET pair for the miR-148 detection assay. The optimized conditions were as follows: in step 1, $40 \mathrm{nM}$ DNA probe, $0.3 \mathrm{U}$ DSN, $50 \mathrm{mM}$ Tris- $\mathrm{HCl}, 15 \mathrm{mM} \mathrm{MgCl}$, and 0.5 $\mathrm{mM}$ DTT, at $\mathrm{pH} 8.0$ and $60{ }^{\circ} \mathrm{C}$, for $2 \mathrm{~h}$; then, in step 2, $1 \mathrm{nM}$ QD-HisDNA conjugates. In the full assay, we observed a positive dose-response in the range of $10^{-15}-10^{-8} \mathrm{M}$ miRNA, shown in Figure 4A. The limit of detection (LOD) was $42 \mathrm{fM}$ (or 1.2 amol of miRNA) based on $3 \sigma$. The saturation point was above $10 \mathrm{nM}$, indicating a relatively large dynamic range. We obtained a 3 order of magnitude improvement in the assay sensitivity through DSN-mediated miRNA recycling compared to that of the nonamplified QD-FRET-based assay (LOD $=72$ $\mathrm{pM}$ ), as shown in Figure S9. This is consistent with previous findings. ${ }^{51,52,71}$ The capability of this assay to distinguish the target miRNA from other miRNA family members was highlighted by the ability of mismatch discrimination, as shown in Figure 4B. Indeed, we observed a significant fluorescence response only in the presence of miR-148, whereas the addition of the other miRNA gave negligible changes. Interestingly, only a slight decrease in the signal was observed from miR-148 with 1 nt mismatch, indicating that DSN still showed cleavage activity on DNA in corresponding duplexes when there was a considerable amount of target existing in the system. Similar results have been reported before. ${ }^{51}$ Furthermore, the specificity can be improved by decreasing the target concentration, as shown in Figure S10. These results indicate that DSN exhibits good selectivity for discriminating among the miRNA family members.

Detection of Endogenous miRNA from Human Cells. To demonstrate the capability to quantify miRNA in a biological sample, we used the DSN-QD method to analyze the endogenous mature miR-21 in different cell lines. The miRNA extracted from human breast cancer cells (MCF-7 and MDA-MB-231) and noncancerous human embryonic kidney cells HEK 293T was diluted and directly used. A standard curve (Figure S11B) was made for quantifying the expression levels of miR-21. Figure S12 shows the absolute concentration of miR-21 measured by the QD-DSN method in comparison with RT-PCR as the reference. The expression levels of miR-21 in MCF-7 and MDA-MB-231 cells determined by both methods were higher than those in HEK 293T cells, indicating that miR-21 is highly upregulated in cancer cells as compared to that in normal cells. To evaluate the performance of our method in terms of sensitivity and specificity, we further constructed a contingency table (Table S2), in which the PCR data set was used as the reference and the upper 95\% confidence interval concentration in HEK 293T given by PCR was used as the criterion of positivity. On the basis of this analysis, the sensitivity and specificity of our assay are 100 and $50 \%$, respectively. The obtained results demonstrate that $88.2 \%$ of the tested biological samples using the QD-DSN method were accurately discriminated compared with the RTPCR detection. Considering the simplicity and homogeneous nature (no washing or separation steps) of our assay, it has promise for application in research or clinical settings, especially with further optimization of the QD surface chemistry, which we feel is currently a limiting factor.

\section{CONCLUSIONS}

In this work, we set out to assess the utility of coemploying enzyme-mediated target recycling and fluorescent QDs for miRNA detection. We have constructed a simple, sensitive, and specific miRNA detection mechanism based on DSN-mediated target recycling and compact QD-DNA constructs generating FRET signals. The DSN-mediated amplification offers unique advantages of high amplification efficiency, isothermal nature, and no nonspecific priming. We demonstrated a detection limit of $42 \mathrm{fM}$ for miR-148 with outstanding selectivity versus mismatched sequences and other miRNAs. In addition, the proposed method was successfully employed for detection of miR-21 using an alternative FRET pair, which was compared with qRT-PCR for the quantitative analysis of miR-21 in biological samples that are rarely interrogated using QD-FRET assays due to the challenging nature of their complex composition. This highly sensitive and specific method therefore shows potential for further development toward a versatile miRNA detection assay. We envisage that further improvements could be made to the detection mechanism with advancements in ultrathin surface chemistries to reduce nonspecific binding while maintaining the fluorescence brightness of QDs.

\section{ASSOCIATED CONTENT}

\section{Supporting Information}

The Supporting Information is available free of charge on the ACS Publications website at DOI: 10.1021/acsami.8b07250.

Details of experiments, oligonucleotide sequences, zwitterionic ligand preparation, QD phase transfer and concentration determination, histidine peptide synthesis and ligation with amine-DNA, characterization of the QD-HisDNA conjugate, DSN activity on reaction time, DTT, $\mathrm{MgCl}_{2}$ concentrations and reaction temperatures, optimization of dye-labeled DNA probe and DSN enzyme, melt curves of duplexes, sensitivity of the assay without DSN amplification, and quantification of miR-21 with RT-PCR and QD-DSN (PDF)

\section{AUTHOR INFORMATION}

\section{Corresponding Author}

*E-mail: m.stevens@imperial.ac.uk.

ORCID $\odot$

Ye Wang: 0000-0002-0525-1832

Philip D. Howes: 0000-0002-1862-8395

Christopher D. Spicer: 0000-0001-8787-578X

Michael R. Thomas: 0000-0001-7795-9648

Yiyang Lin: 0000-0003-2017-190X

Molly M. Stevens: 0000-0002-7335-266X 


\section{Present Addresses}

${ }^{\ddagger}$ Department of Medical Biochemistry and Biophysics, Karolinska Institutet, SE-171 77, Stockholm, Sweden.

${ }^{\dagger}$ Department of Chemistry and Applied Biosciences, ETH Zürich, CH-8093 Zürich, Switzerland (P.D.H.).

\section{Notes}

The authors declare no competing financial interest. Raw data are available online at DOI: 10.5281/zenodo. 1341087.

\section{ACKNOWLEDGMENTS}

This work was kindly supported by the i-sense EPSRC IRC in Early Warning Sensing Systems for Infectious Disease grant (EP/K031953/1). Y.W. acknowledges support from the China Scholarship Council. P.D.H. acknowledges support from European Union's Horizon 2020 research and innovation program through the Individual Marie Skłodowska-Curie Fellowship "Ampidots" under grant agreement no. 701994. E.K. acknowledges support from Basic Science Research Program through the National Research Foundation of Korea (NRF) funded by the Ministry of Education (2015R1A6A3A03018919). I.J.P. acknowledges support from the Whitaker International Program, Institute of International Education, United States. M.M.S. acknowledges the ERC Consolidator grant "Naturale CG" (616417) and the EPSRC grant "Bio-functionalised nanomaterials for ultrasensitive biosensing" (EP/K020641/1). The authors acknowledge the use of the characterization facilities within the Harvey Flower Electron Microscopy Suite (Department of Materials) at Imperial College London.

\section{REFERENCES}

(1) Lu, J.; Getz, G.; Miska, E. A.; Alvarez-Saavedra, E.; Lamb, J.; Peck, D.; Sweet-Cordero, A.; Ebert, B. L.; Mak, R. H.; Ferrando, A. A.; Downing, J. R.; Jacks, T.; Horvitz, H. R.; Golub, T. R. MicroRNA Expression Profiles Classify Human Cancers. Nature 2005, 435, 834838.

(2) Nie, M.; Deng, Z.-L.; Liu, J.; Wang, D.-Z. Noncoding RNAs, Emerging Regulators of Skeletal Muscle Development and Diseases. BioMed Res. Int. 2015, 2015, No. 676575.

(3) Calin, G. A.; Croce, C. M. MicroRNA Signatures in Human Cancers. Nat. Rev. Cancer 2006, 6, 857-866.

(4) Keller, A.; Leidinger, P.; Bauer, A.; ElSharawy, A.; Haas, J.; Backes, C.; Wendschlag, A.; Giese, N.; Tjaden, C.; Ott, K.; Werner, J.; Hackert, T.; Ruprecht, K.; Huwer, H.; Huebers, J.; Jacobs, G.; Rosenstiel, P.; Dommisch, H.; Schaefer, A.; Muller-Quernheim, J.; Wullich, B.; Keck, B.; Graf, N.; Reichrath, J.; Vogel, B.; Nebel, A.; Jager, S. U.; Staehler, P.; Amarantos, I.; Boisguerin, V.; Staehler, C.; Beier, M.; Scheffler, M.; Buchler, M. W.; Wischhusen, J.; Haeusler, S. F. M.; Dietl, J.; Hofmann, S.; Lenhof, H.-P.; Schreiber, S.; Katus, H. A.; Rottbauer, W.; Meder, B.; Hoheisel, J. D.; Franke, A.; Meese, E. Toward the Blood-Borne miRNome of Human Diseases. Nat. Methods 2011, 8, 841-843.

(5) Alivisatos, P. The Use of Nanocrystals in Biological Detection. Nat. Biotechnol. 2004, 22, 47-52.

(6) Spicer, C. D.; Jumeaux, C.; Gupta, B.; Stevens, M. M. Peptide and Protein Nanoparticle Conjugates: Versatile Platforms For Biomedical Applications. Chem. Soc. Rev. 2018, 47, 3574-3620.

(7) Howes, P. D.; Chandrawati, R.; Stevens, M. M. Colloidal Nanoparticles as Advanced Biological Sensors. Science 2014, 346, No. 1247390.

(8) Bruchez, M., Jr.; Moronne, M.; Gin, P.; Weiss, S.; Alivisatos, A. P. Semiconductor Nanocrystals as Fluorescent Biological Labels. Science 1998, 281, 2013-2016.
(9) Chan, W. C. W.; Nie, S. Quantum Dot Bioconjugates for Ultrasensitive Nonisotopic Detection. Science 1998, 281, 2016-2018. (10) Han, M.; Gao, X.; Su, J. Z.; Nie, S. Quantum-Qot-tagged Microbeads for Multiplexed Optical Coding of Biomolecules. Nat. Biotechnol. 2001, 19, 631-635.

(11) Ghadiali, J. E.; Lowe, S. B.; Stevens, M. M. Quantum-DotBased FRET Detection of Histone Acetyltransferase Activity. Angew. Chem., Int. Ed. 2011, 50, 3417-3420.

(12) Hildebrandt, N.; Spillmann, C. M.; Algar, W. R.; Pons, T.; Stewart, M. H.; Oh, E.; Susumu, K.; Diaz, S. A.; Delehanty, J. B.; Medintz, I. L. Energy Transfer with Semiconductor Quantum Dot Bioconjugates: A Versatile Platform for Biosensing, Energy Harvesting, and Other Developing Applications. Chem. Rev. 2017, 117, 536711.

(13) Bhuckory, S.; Mattera, L.; Wegner, K. D.; Qiu, X.; Wu, Y. T.; Charbonniere, L. J.; Reiss, P.; Hildebrandt, N. Direct Conjugation of Antibodies To the $\mathrm{ZnS}$ Shell of Quantum Dots for FRET Immunoassays with Low Picomolar Detection Limits. Chem. Commun. 2016, 52, 14423-14425.

(14) Qiu, X.; Wegner, K. D.; Wu, Y.-T.; van Bergen en Henegouwen, P. M. P.; Jennings, T. L.; Hildebrandt, N. Nanobodies and Antibodies for Duplexed EGFR/HER2 Immunoassays Using Terbium-to-Quantum Dot FRET. Chem. Mater. 2016, 28, 82568267.

(15) Wegner, K. D.; Jin, Z.; Lindén, S.; Jennings, T. L.; Hildebrandt, N. Quantum-Dot-Based Förster Resonance Energy Transfer Immunoassay for Sensitive Clinical Diagnostics of Low-Volume Serum Samples. ACS Nano 2013, 7, 7411-7419.

(16) Claussen, J. C.; Hildebrandt, N.; Susumu, K.; Ancona, M. G.; Medintz, I. L. Complex Logic Functions Implemented with Quantum Dot Bionanophotonic Circuits. ACS Appl. Mater. Interfaces 2014, 6, 3771-3778.

(17) Algar, W. R.; Wegner, D.; Huston, A. L.; Blanco-Canosa, J. B.; Stewart, M. H.; Armstrong, A.; Dawson, P. E.; Hildebrandt, N.; Medintz, I. L. Quantum Dots as Simultaneous Acceptors and Donors in Time-Gated Förster Resonance Energy Transfer Relays: Characterization and Biosensing. J. Am. Chem. Soc. 2012, 134, 1876-1891.

(18) Zhang, C.-Y.; Yeh, H.-C.; Kuroki, M. T.; Wang, T.-H. SingleQuantum-Dot-Based DNA Nanosensor. Nat. Mater. 2005, 4, 826831.

(19) Su, S.; Fan, J.; Xue, B.; Yuwen, L.; Liu, X.; Pan, D.; Fan, C.; Wang, L. DNA-Conjugated Quantum Dot Nanoprobe for HighSensitivity Fluorescent Detection of DNA and micro-RNA. ACS Appl. Mater. Interfaces 2014, 6, 1152-1157.

(20) Crut, A.; Géron-Landre, B.; Bonnet, I.; Bonneau, S.; Desbiolles, P.; Escudé, C. Detection of Single DNA Molecules by Multicolor Quantum-Dot End-Labeling. Nucleic Acids Res. 2005, 33, No. e98.

(21) Page, L. E.; Zhang, X.; Tyrakowski, C. M.; Ho, C.-T.; Snee, P. T. Synthesis and Characterization of DNA-Quantum Dot Conjugates For the Fluorescence Ratiometric Detection of Unlabelled DNA. Analyst 2016, 141, 6251-6258.

(22) Sapountzi, E. A.; Tragoulias, S. S.; Kalogianni, D. P.; Ioannou, P. C.; Christopoulos, T. K. Lateral Flow Devices for Nucleic Acid Analysis Exploiting Quantum Dots as Reporters. Anal. Chim. Acta 2015, 864, 48-54.

(23) Gliddon, H. D.; Howes, P. D.; Kaforou, M.; Levin, M.; Stevens, M. M. A Nucleic Acid Strand Displacement System For the Multiplexed Detection of Tuberculosis-Specific mRNA using Quantum Dots. Nanoscale 2016, 8, 10087-10095.

(24) Song, W.; Qiu, X.; Lau, C.; Lu, J. Quantum Dot-Enhanced Detection of Dual Short RNA Sequences Via One-Step TemplateDependent Surface Hybridization. Anal. Chim. Acta 2012, 735, 114120.

(25) Zhang, Y.; Zhang, C.-y. Sensitive Detection of microRNA with Isothermal Amplification and a Single-Quantum-Dot-Based Nanosensor. Anal. Chem. 2012, 84, 224-231.

(26) Wang, D.; Hu, L.; Zhou, H.; Abdel-Halim, E. S.; Zhu, J.-J. Molecular Beacon Structure Mediated Rolling Circle Amplification 
for Ultrasensitive Electrochemical Detection of microRNA Based on Quantum Dots Tagging. Electrochem. Commun. 2013, 33, 80-83.

(27) Zhu, W.; Su, X.; Gao, X.; Dai, Z.; Zou, X. A Label-Free and PCR-Free Electrochemical Assay For Multiplexed MicroRNA Profiles By Ligase Chain Reaction Coupling With Quantum Dots Barcodes. Biosens. Bioelectron. 2014, 53, 414-419.

(28) Zeng, Y.-p.; Zhu, G.; Yang, X.-y.; Cao, J.; Jing, Z.-1.; Zhang, C.y. A Quantum Dot-Based MicroRNA Nanosensor For Point Mutation Assays. Chem. Commun. 2014, 50, 7160-7162.

(29) Jou, A. F.-j.; Lu, C.-H.; Ou, Y.-C.; Wang, S.-S.; Hsu, S.-L.; Willner, I.; Ho, J.-a. A. Diagnosing the MiR-141 Prostate Cancer Biomarker Using Nucleic Acid-Functionalized CdSe/ZnS QDs and Telomerase. Chem. Sci. 2015, 6, 659-665.

(30) Zhang, H.; Liu, Y.; Fu, X.; Yuan, L.; Zhu, Z. Microfluidic BeadBased Assay For MicroRNAs Using Quantum Dots as Labels and Enzymatic Amplification. Microchim. Acta 2015, 182, 661-669.

(31) Qiu, X.; Hildebrandt, N. Rapid and Multiplexed MicroRNA Diagnostic Assay Using Quantum Dot-Based Förster Resonance Energy Transfer. ACS Nano 2015, 9, 8449-8457.

(32) Geng, Y.; Lin, D.; Shao, L.; Yan, F.; Ju, H. Cellular Delivery of Quantum Dot-Bound Hybridization Probe for Detection of Intracellular Pre-MicroRNA Using Chitosan/Poly $(\gamma$-Glutamic Acid) Complex as a Carrier. PLoS One 2013, 8, No. e65540.

(33) Liang, R.-Q.; Li, W.; Li, Y.; Tan, C.-Y.; Li, J.-X.; Jin, Y.-X.; Ruan, K.-C. An Oligonucleotide Microarray For MicroRNA Expression Analysis Based On Labeling RNA With Quantum Dot and Nanogold Probe. Nucleic Acids Res. 2005, 33, No. e17.

(34) Zhu, J.; Feng, X.; Lou, J.; Li, W.; Li, S.; Zhu, H.; Yang, L.; Zhang, A.; He, L.; Li, C. Accurate Quantification of microRNA via Single Strand Displacement Reaction on DNA Origami Motif. PLoS One 2013, 8, No. e69856.

(35) Cheng, Y.; Lei, J.; Chen, Y.; Ju, H. Highly Selective Detection Of MicroRNA Based On Distance-Dependent Electrochemiluminescence Resonance Energy Transfer Between CdTe Nanocrystals and Au Nanoclusters. Biosens. Bioelectron. 2014, 51, 431-436.

(36) Qiu, X.; Guo, J.; Jin, Z.; Petreto, A.; Medintz, I. L.; Hildebrandt, N. Multiplexed Nucleic Acid Hybridization Assays Using SingleFRET-Pair Distance-Tuning. Small 2017, No. 1700332.

(37) Lv, S.; Chen, F.; Chen, C.; Chen, X.; Gong, H.; Cai, C. A Novel CdTe Quantum Dots Probe Amplified Resonance Light Scattering Signals to Detect MicroRNA-122. Talanta 2017, 165, 659-663.

(38) Tagit, O.; Hildebrandt, N. Fluorescence Sensing of Circulating Diagnostic Biomarkers Using Molecular Probes and Nanoparticles. ACS Sens. 2017, 2, 31-45.

(39) Deng, H.; Liu, Q.; Wang, X.; Huang, R.; Liu, H.; Lin, Q.; Zhou, X.; Xing, D. Quantum Dots-Labeled Strip Biosensor For Rapid and Sensitive Detection Of MicroRNA Based On Target-Recycled Nonenzymatic Amplification Strategy. Biosens. Bioelectron. 2017, 87, 931-940.

(40) Yuan, R.; Yu, X.; Zhang, Y.; Xu, L.; Cheng, W.; Tu, Z.; Ding, S. Target-Triggered DNA Nanoassembly On Quantum Dots and DNAzyme-Modulated Double Quenching For Ultrasensitive MicroRNA Biosensing. Biosens. Bioelectron. 2017, 92, 342-348.

(41) Pathak, S.; Choi, S.-K.; Arnheim, N.; Thompson, M. E. Hydroxylated Quantum Dots as Luminescent Probes for in Situ Hybridization. J. Am. Chem. Soc. 2001, 123, 4103-4104.

(42) Thaxton, C. S.; Hill, H. D.; Georganopoulou, D. G.; Stoeva, S. I.; Mirkin, C. A. A Bio-Bar-Code Assay Based upon DithiothreitolInduced Oligonucleotide Release. Anal. Chem. 2005, 77, 8174-8178.

(43) Hurst, S. J.; Lytton-Jean, A. K. R.; Mirkin, C. A. Maximizing DNA Loading on a Range of Gold Nanoparticle Sizes. Anal. Chem. 2006, 78, 8313-8318.

(44) Molnár, M.; Ning, Z.-J.; Chen, Y.; Friberg, P.; Gan, L.-M.; Fu, Y. Effects of $\mathrm{K}^{+}$and $\mathrm{Na}^{+}$Ions On The Fluorescence of Colloidal $\mathrm{CdSe} / \mathrm{CdS}$ and CdSe/ZnS Quantum Dots. Sens. Actuators, B 2011, $155,823-830$.

(45) Li, L.; Chen, Y.; Tian, G.; Akpe, V.; Xu, H.; Gan, L.-M.; Skrtic, S.; Luo, Y.; Brismar, H.; Fu, Y. Reversible Modification of CdSe-
CdS/ZnS Quantum Dot Fluorescence by Surrounding $\mathrm{Ca}^{2+}$ Ions. J. Phys. Chem. C 2014, 118, 10424-10433.

(46) Anisimova, V. E.; Rebrikov, D. V.; Shagin, D. A.; Kozhemyako, V. B.; Menzorova, N. I.; Staroverov, D. B.; Ziganshin, R.; Vagner, L. L.; Rasskazov, V. A.; Lukyanov, S. A.; Shcheglov, A. S. Isolation, Characterization and Molecular Cloning of Duplex-Specific Nuclease From The Hepatopancreas of The Kamchatka Crab. BMC Biochem. 2008, 9, 14.

(47) Song, H.; Wang, Q.; Guo, Y.; Liu, S.; Song, R.; Gao, X.; Dai, L.; Li, B.; Zhang, D.; Cheng, J. Microarray Analysis of MicroRNA Expression In Peripheral Blood Mononuclear Cells of Critically Ill Patients with Influenza A (H1N1). BMC Infect. Dis. 2013, 13, 257.

(48) Kumarswamy, R.; Volkmann, I.; Thum, T. Regulation and function of miRNA-21 in health and disease. RNA Biol. 2011, 8, 706713.

(49) Susumu, K.; Oh, E.; Delehanty, J. B.; Blanco-Canosa, J. B.; Johnson, B. J.; Jain, V.; Hervey, W. J.; Algar, W. R.; Boeneman, K.; Dawson, P. E.; Medintz, I. L. Multifunctional Compact Zwitterionic Ligands for Preparing Robust Biocompatible Semiconductor Quantum Dots and Gold Nanoparticles. J. Am. Chem. Soc. 2011, 133, 9480-9496.

(50) Prasuhn, D. E.; Blanco-Canosa, J. B.; Vora, G. J.; Delehanty, J. B.; Susumu, K.; Mei, B. C.; Dawson, P. E.; Medintz, I. L. Combining Chemoselective Ligation with Polyhistidine-Driven Self-Assembly for the Modular Display of Biomolecules on Quantum Dots. ACS Nano 2010, 4, 267-278

(51) Kim, E.; Howes, P. D.; Crowder, S. W.; Stevens, M. M. MultiAmplified Sensing of MicroRNA by a Small DNA Fragment-Driven Enzymatic Cascade Reaction. ACS Sens. 2017, 2, 111-118.

(52) Yin, B.-C.; Liu, Y.-Q.; Ye, B.-C. One-Step, Multiplexed Fluorescence Detection of microRNAs Based on Duplex-Specific Nuclease Signal Amplification. J. Am. Chem. Soc. 2012, 134, 50645067.

(53) Hess, K. L.; Oh, E.; Tostanoski, L. H.; Andorko, J. I.; Susumu, K.; Deschamps, J. R.; Medintz, I. L.; Jewell, C. M. Engineering Immunological Tolerance Using Quantum Dots to Tune the Density of Self-Antigen Display. Adv. Funct. Mater. 2017, 27, No. 1700290.

(54) Vranish, J. N.; Ancona, M. G.; Oh, E.; Susumu, K.; Medintz, I. L. Enhancing Coupled Enzymatic Activity By Conjugating One Enzyme to A Nanoparticle. Nanoscale 2017, 9, 5172-5187.

(55) Agarwal, R.; Domowicz, M. S.; Schwartz, N. B.; Henry, J.; Medintz, I.; Delehanty, J. B.; Stewart, M. H.; Susumu, K.; Huston, A. L.; Deschamps, J. R.; Dawson, P. E.; Palomo, V.; Dawson, G. Delivery and Tracking of Quantum Dot Peptide Bioconjugates in an Intact Developing Avian Brain. ACS Chem. Neurosci. 2015, 6, 494-504.

(56) Liu, D.; Snee, P. T. Water-Soluble Semiconductor Nanocrystals Cap Exchanged with Metalated Ligands. ACS Nano 2011, 5, 546550.

(57) Aldeek, F.; Safi, M.; Zhan, N. Q.; Palui, G.; Mattoussi, H. Understanding the Self-Assembly of Proteins onto Gold Nanoparticles and Quantum Dots Driven by Metal-Histidine Coordination. ACS Nano 2013, 7, 10197-10210.

(58) Breger, J. C.; Ancona, M. G.; Walper, S. A.; Oh, E.; Susumu, K.; Stewart, M. H.; Deschamps, J. R.; Medintz, I. L. Understanding How Nanoparticle Attachment Enhances Phosphotriesterase Kinetic Efficiency. ACS Nano 2015, 9, 8491-8503.

(59) Dirksen, A.; Dawson, P. E. Rapid Oxime and Hydrazone Ligations with Aromatic Aldehydes for Biomolecular Labeling. Bioconjugate Chem. 2008, 19, 2543-2548.

(60) Spicer, C. D.; Davis, B. G. Selective chemical protein modification. Nat. Commun. 2014, 5, No. 4740.

(61) Pons, T.; Medintz, I. L.; Wang, X.; English, D. S.; Mattoussi, H. Solution-Phase Single Quantum Dot Fluorescence Resonance Energy Transfer. J. Am. Chem. Soc. 2006, 128, 15324-15331.

(62) Boeneman, K.; Deschamps, J. R.; Buckhout-White, S.; Prasuhn, D. E.; Blanco-Canosa, J. B.; Dawson, P. E.; Stewart, M. H.; Susumu, K.; Goldman, E. R.; Ancona, M.; Medintz, I. L. Quantum Dot DNA Bioconjugates: Attachment Chemistry Strongly Influences the Resulting Composite Architecture. ACS Nano 2010, 4, 7253-7266. 
(63) Shagin, D. A.; Rebrikov, D. V.; Kozhemyako, V. B.; Altshuler, I. M.; Shcheglov, A. S.; Zhulidov, P. A.; Bogdanova, E. A.; Staroverov, D. B.; Rasskazov, V. A.; Lukyanov, S. A Novel Method for SNP Detection Using a New Duplex-Specific Nuclease From Crab Hepatopancreas. Genome Res. 2002, 12, 1935-1942.

(64) Shen, W.; Deng, H.; Ren, Y.; Gao, Z. A Real-Time Colorimetric Assay For Label-Free Detection of MicroRNAs Down to SubFemtomolar Levels. Chem. Commun. 2013, 49, 4959-4961.

(65) Wang, S.; Fu, B.; Wang, J.; Long, Y.; Zhang, X.; Peng, S.; Guo, P.; Tian, T.; Zhou, X. Novel Amplex Red Oxidases Based on Noncanonical DNA Structures: Property Studies and Applications in MicroRNA Detection. Anal. Chem. 2014, 86, 2925-2930.

(66) Yan, L.; Yan, Y.; Pei, L.; Wei, W.; Zhao, J. A G-quadruplex DNA-based, Label-Free and Ultrasensitive Strategy for microRNA Detection. Sci. Rep. 2014, 4, No. 7400.

(67) Hao, N.; Dai, P.-P.; Yu, T.; Xu, J.-J.; Chen, H.-Y. A Dual Target-Recycling Amplification Strategy for Sensitive Detection of MicroRNAs Based on Duplex-Specific Nuclease and Catalytic Hairpin Assembly. Chem. Commun. 2015, 51, 13504-13507.

(68) Shen, W.; Yeo, K. H.; Gao, Z. A Simple and Highly Sensitive Fluorescence Assay for MicroRNAs. Analyst 2015, 140, 1932-1938.

(69) Li, Y.; Zhang, J.; Zhao, J.; Zhao, L.; Cheng, Y.; Li, Z. A Simple Molecular Beacon With Duplex-Specific Nuclease Amplification For Detection of MicroRNA. Analyst 2016, 141, 1071-1076.

(70) Lv, W.; Zhao, J.; Situ, B.; Li, B.; Ma, W.; Liu, J.; Wu, Z.; Wang, W.; Yan, X.; Zheng, L. A Target-Triggered Dual Amplification Strategy for Sensitive Detection of MicroRNA. Biosens. Bioelectron. 2016, 83, 250-255.

(71) Degliangeli, F.; Kshirsagar, P.; Brunetti, V.; Pompa, P. P.; Fiammengo, R. Absolute and Direct MicroRNA Quantification Using DNA-Gold Nanoparticle Probes. J. Am. Chem. Soc. 2014, 136, 22642267. 